\title{
Why are capital flows so much more volatile in emerging than in developed countries?
}

\author{
Fernando A. Broner \\ CREI, Universitat Pompeu Fabra, \\ and University of Maryland
}

\author{
Roberto Rigobon
}

MIT and NBER

October 2004

\begin{abstract}
The standard deviations of capital flows to emerging countries are 80 percent higher than those to developed countries. First, we show that very little of this difference can be explained by more volatile fundamentals or by higher sensitivity to fundamentals. Second, we show that most of the difference in volatility can be accounted for by three characteristics of capital flows: (i) capital flows to emerging countries are more subject to occasional large negative shocks ("crises") than those to developed countries, (ii) shocks are subject to contagion, and (iii) - the most important one - shocks to capital flows to emerging countries are more persistent than those to developed countries. Finally, we study a number of country characteristics to determine which are most associated with capital flow volatility. Our results suggest that underdevelopment of domestic financial markets, weak institutions, and low income per capita, are all associated with capital flow volatility.
\end{abstract}

Keywords: Capital flows, emerging countries, volatility, crises, contagion, persistence.

JEL Classification: F21, F32, F37, G15.

Prepared for the Eight Annual Conference of the Central Bank of Chile, "External Financial Vulnerability and Preventive Policies," Santiago, Chile, August 10 and 11, 2004. We thank Alvaro Aguirre, Ricardo Caballero, and Eduardo Levy-Yeyati for very helpful comments. 


\section{Introduction}

One of the most studied subjects in open macroeconomics is the determinants of capital flows. In general, most papers are concerned with the estimation of the following regression:

$$
K_{i, t}=c_{i}+X_{i, t} A+\varepsilon_{i, t}
$$

where the left hand side is some measurement of capital flows (as a percentage of GDP, or as changes), and where in the right hand side several time and cross sectional controls are introduced, such as GDP growth, real exchange rates, the international interest rate, terms of trade, availability of international funds, some measure of credit constraints, etc. In this context, almost the entire literature focuses on the properties of $A$, such as what the signs and significance of the coefficients are, which the most important determinants are, etc. In this paper, we take a different perspective: we concentrate on the explanatory power of fundamentals and on the properties of the residuals, i.e. the portion of capital flows that is unexplained by fundamentals.

This new dimension allows us to uncover a pattern that has escaped the literature: the fundamentals have some explanatory power for capital flows (the R-squares of the regressions are not zero) but this explanatory power is quite small, especially when considering that problems of endogeneity and omitted variables likely imply that we are overestimating the explanatory power of these variables; furthermore, the ratio of standard deviations between emerging country residuals and developed countries residuals is very stable to different measures of capital flows, controls for domestic and external shocks, and non-linearities and asymmetries. We find that capital flows to emerging countries are 80 percent more volatile than those to developed economies, and controlling for a series of macroeconomic variables we are able to reduce this ratio to 62 percent. On the other hand, we find that non-fundamental variables, such as outliers, lags, and contagion effects, are able to reduce this ratio to 16 percent. $^{1}$

Hausmann, Panizza and Rigobon (2004) find very similar patterns in real exchange rate volatilities. The stylized facts in this paper are not of the same nature because we controlled for exchange rate movements and still the high volatility of the capital flows remained. 
The paper is organized as follows: Section II reports the difference in volatility of capital flows to emerging vs. developed countries. Section III reports the effect of controlling for macroeconomic variables. Section IV reports some statistical regularities of the residuals. Section V studies the determinants of the unconditional standard deviation. Section VI concludes.

\section{Volatility in emerging and developed countries}

\section{A. Data}

We collected data on total capital flows measured as the capital account in the BOP statistics, GDP, inflation, exchange rate, nominal interest rates, and the terms of trade, yearly for the period 1965-2003 from IFS. The countries included in the data set are 23 industrialized economies (USA, UK, Austria, Belgium, Denmark, France, Germany, Italy, Netherlands, Norway, Sweden, Switzerland, Canada, Japan, Finland, Greece, Iceland, Ireland, Portugal, Spain, Australia, New Zealand, and Israel) ${ }^{2}, 7$ Latin American countries (Argentina, Brazil, Chile, Colombia, Mexico, Uruguay, and Venezuela), 9 Asian Economies (Hong Kong, India, Indonesia, Korea, Malaysia, Philippines, Singapore, Thailand, China), 13 Transition Economies (Bulgaria, Russia, Ukraine, Czech Republic, Slovak Republic, Estonia, Latvia, Hungary, Lithuania, Croatia, Slovenia, Poland, Romania), and 6 other countries (Turkey, South Africa, Egypt, Morocco, Nigeria, Tunisia).

These countries are divided in two broad groups: industrialized and emerging countries. For the analysis of common components, the emerging economies are also divided into Latin America, Asia, Transition, and Others, since we test for contagion effects within these groups.

We also collected information on real income per capita from Penn World Tables; on financial development (ratios of private domestic credit and liquid liabilities over GDP) from Loayza, Fajnzylber and Calderón (2004); and on the quality of institutions from International Country Risk Guide. ${ }^{3}$

These are the OECD countries plus Israel minus Mexico and Korea. The results are not sensitive to this choice. We thank Norman Loayza for providing us with the data on financial development and quality of institutions. 


\section{B. Volatility: A first pass.}

In this section we document the excess volatility that is present in the capital flows to emerging countries, to then explore its determinants in the rest of the paper. In Figure 1 we show the standard deviation of capital flows as a percentage of GDP, calculated country by country.

Figure 1: Standard deviations of capital flows

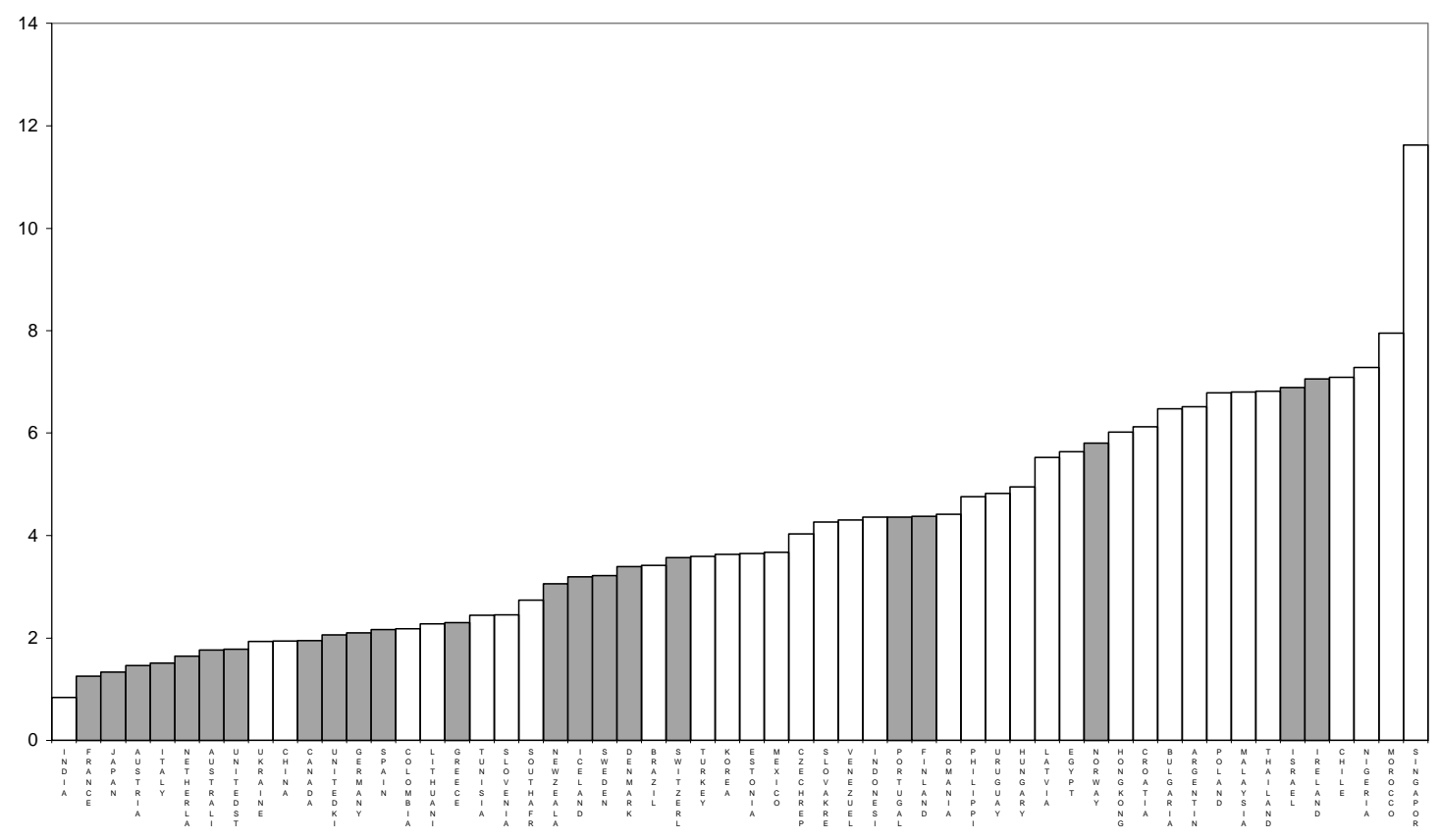

The countries have been sorted from the smallest standard deviation to the highest. The gray bars indicate developed countries and the clear bars emerging countries. As can be easily seen, the countries located in the left-hand side of the Figure are mostly developed countries, while the emerging countries are concentrated in the right hand side of the figure. Table 1 shows the standard deviation of capital flows for each of the two groups. Capital flows as a percentage of GDP in emerging countries are 80 percent more volatile than those to developed countries. In addition, capital flows to both groups of countries are left skewed, substantially more so for emerging countries.

Table 1: Statistics of capital flows for emerging and developed countries

\begin{tabular}{|l|c|c|}
\hline & st dev & skewness \\
\hline developed countries & 3.175 & -0.502 \\
\hline emerging countries & 5.677 & -0.760 \\
\hline ratio & 1.79 & 1.52 \\
\hline
\end{tabular}


What are the possible explanations for this pattern? There are at least three possible explanations: First, emerging countries might be hit by fundamental shocks that have different stochastic properties than those that affect developed countries and the capital flows might just reflect those properties. Second, capital flows to emerging and developed countries might respond differently to similar fundamental shocks. Third, emerging countries might be subject to larger sources of non-fundamental shocks, such as crises, persistence, and contagion.

With respect to the first explanation, emerging countries could be on average subject to larger and more left skewed fundamental shocks. Indeed, on average, emerging economies are subject to larger and more skewed shocks in terms of inflation, interest rates, real exchange rates, output, and terms of trade. In this case, the difference in the characteristics of capital flows should be reflected in differences in the behavior of fundamentals. We study this possibility, including the role of non-linearities and asymmetries in explaining the higher volatility of capital flows.

With respect to the second explanation, emerging countries might respond more than developed countries to similar fundamental shocks. In this case, there should be a difference in the sensitivity of flows to fundamentals. For example, there is a large literature that studies the amplification of shocks when financial markets are less developed, such amplification means that capital flows would be more volatile for the same shocks.

Finally, maybe there are other, non-fundamental shocks that explain the difference in volatility. In this case, we should find differences in the behavior of the portion of capital flows that is unexplained by fundamental shocks (i.e. residuals). We analyze a number of possibilities: crises (left skewed residuals), contagion (correlated residuals), and persistence of shocks (lags).

In this paper we provide two complementary types of evidence. First, which factors account for the standard deviation of capital flows in emerging and developed countries (panel regressions)? The purpose of this exercise is to decompose the ratio of the standard deviations to determine the relative weight of the explanations mentioned in the previous paragraphs. These are not variance decompositions because the regressors are not orthogonal, but the decomposition will be informative. Second, what characteristics of emerging countries lead to higher volatility of capital flows (crosssectional volatility regressions)? 
Our interpretation of the excess volatility of emerging countries is that there exists a specification problem, and that the higher standard deviation reflects omitted variables. This is almost a tautological interpretation, but one that guides us in the empirical strategy that we follow in the following sections. We will introduce variable by variable, and test "theory" by "theory," trying to reduce the excess volatility of residuals from 80 percent to close to zero.

\section{Volatility and fundamentals}

\section{A. Domestic factors}

There are many fundamental variables that can have an effect on capital flows: terms of trade shocks, productivity shocks, time preference shocks, initial endowments, etc. Although it is impossible to construct a large panel that includes emerging countries with all relevant fundamentals, it is likely that those fundamentals be reflected in macroeconomic variables (for example, productivity shocks in GDP and time preference shocks in interest rates). We consider GDP, inflation, interest rate, exchange rates, and terms of trade. Obviously, if we tried to identify causation we would face a problem of endogeneity and omitted variables. But our objective is not to resolve the problem of identification but to determine to what extent fundamental variables could be responsible for the volatility of capital flows. Since we find that these variables "explain" very little of the volatility of capital flows, the possible existence of reverse causation and omitted variables suggests that in reality fundamental shocks account for even less of the volatility of capital flows than implied by our low $R^{2}$.

We estimate panel regressions of the form

$$
K_{i, t}=c_{i}+X_{i, t} A_{i}+\varepsilon_{i, t}
$$

where $X_{i, t}$ are the controls or macroeconomic variables. We restrict the coefficients $A_{i}$ to be the same within the two groups of countries since we do not have enough data to estimate country specific coefficients. However, by allowing the coefficients to differ between emerging and developed countries, we allow for different sensitivities to play a role in explaining the higher volatility of capital flows to emerging countries. 
Note that this is a reduced form representation and, therefore, no interpretation to the coefficients $A_{i}$ should be given. Clearly, several of the variables that we include in the right hand side are endogenous to capital inflows, such as the interest rate and the exchange rate. Therefore, the estimation of $A_{i}$ suffers from simultaneous equations bias. However, in this paper we are concerned with the possible explanatory power of the fundamentals and with the properties of the residuals, not with the coefficients per se. By projecting the capital flows into the endogenous variables we tend to maximize their explanatory power, reducing the standard deviation of the residuals to a minimum. As a result, the "true" explanatory power of any set of fundamentals we consider should be between zero and the result we report.

Table 2 reports the results of running the regression for different sets of macroeconomic variables. We included the macroeconomic variables one by one to try to understand their incremental effect on the overall variance, standard deviation, and skewness. The control variables are GDP per capita (in logs), the exchange rate depreciation, inflation rate, the domestic interest rate, and the terms of trade measure by both the price of imports or price of exports (in logs). ${ }^{4,5}$

Table 2: Statistics of capital flows - domestic macroeconomic variables

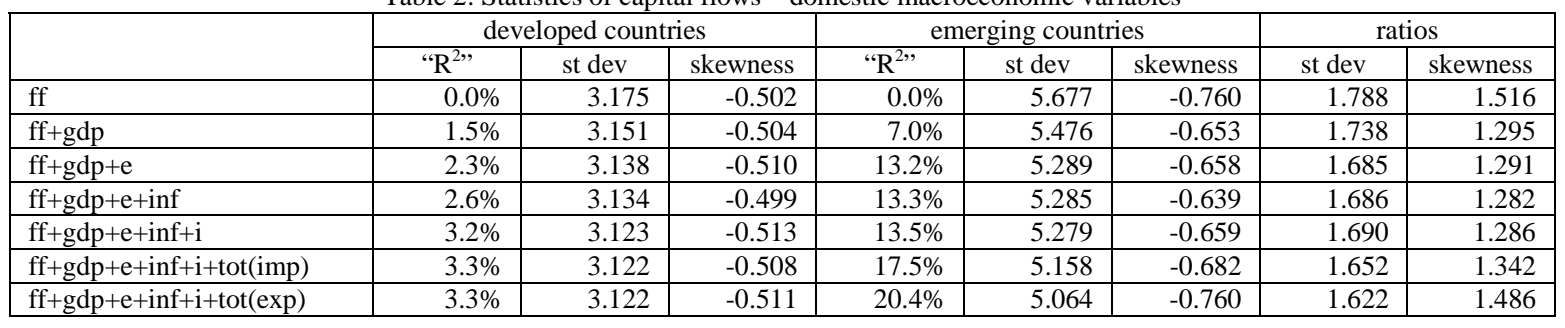

The first row in Table 2 is our benchmark - where we control for fixed effects only. ${ }^{6}$ From the second to the sixth rows we introduce macroeconomic variables one by one into the specification. ${ }^{7}$ For

The regressions are balanced, in the sense that we only use observations for which all control variables are available. So the number of observations is the same in all specifications.

We tried including growth rate of GDP and growth rate of terms of trade instead of levels, obtaining the same results.

In principle, to compute the standard deviation of capital flows for the countries in each group we would not need to include a constant term for each country. However, in this case the standard deviation of the residual would reflect both the time series volatility within each country and the crosssectional variation across countries. We do not believe that the latter is part of what is usually understood as volatility of capital flows. That is why we always include country fixed effects and the fixed effect regression is the benchmark against which we compare all the other regressions. 
each group of countries, the first column is the fraction of the variance of the residuals that is explained relative to the specification in which we only have fixed effects (first row) ${ }^{8}$, the second column is the standard deviation of the residuals, and the third column is the skewness of the residuals. The first set of columns reports the results for developed countries, the second set of columns reports the results for emerging countries, and the last two columns are the ratio of the standard deviation and skewness of residuals for the two groups of countries.

The first result worth highlighting is that fundamentals may explain some of the capital flows

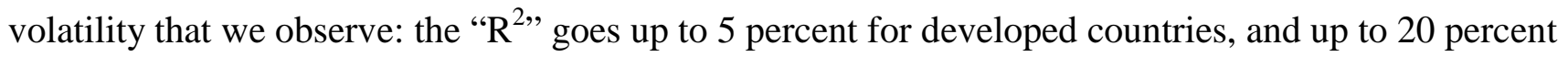
for emerging countries. The second result, and the on which we will focus, is that the ratio of the standard deviation of residuals for emerging and developed economies is remarkably stable to the introduction of these fundamentals.

In Figure 2, we summarize these results. We show the standard deviations of the residuals as well as the ratio of standard deviations for all the specifications. As can be appreciated, the standard deviation of residuals for emerging countries is reduced by around 10 percent, while the ratio of the standard deviations is reduced from 1.788 to 1.622 .

The conclusion of this exercise is that even though domestic macroeconomic variables may have some explanatory power for capital flows; they contribute little to explaining the ratio of standard deviations across groups.

Finally, notice that the skewness of residuals is only slightly affected by the introduction of macroeconomic variables. It is interesting that the skewness associated with exchange rate depreciations is unable to explain the skewness in the data. One of the most obvious reactions to the stylized facts in the previous section is that crises might be an important component explaining the skewness and volatility of the capital flows to emerging countries. However, these results suggest that these effects cannot be accounted for by the skewness and volatility in macroeconomic variables. We come back to this point later. In summary, the higher volatility and skewness of capital flows to

We also estimated specifications in which unemployment is included. Because including unemployment reduced the sample significantly and it did not change the results at all, we decided to exclude those specifications. Results are available from the authors.

This is more informative than $\mathrm{R}^{2}$ since, given our focus on volatility, we are not interested in the fraction of the variance explained by fixed effects. 
emerging countries cannot be accounted for a different behavior of, or different response to, macroeconomic variables.

Figure 2: Standard deviation for each group for all specifications.

Ratio of standard deviations is measured on the right hand axis.

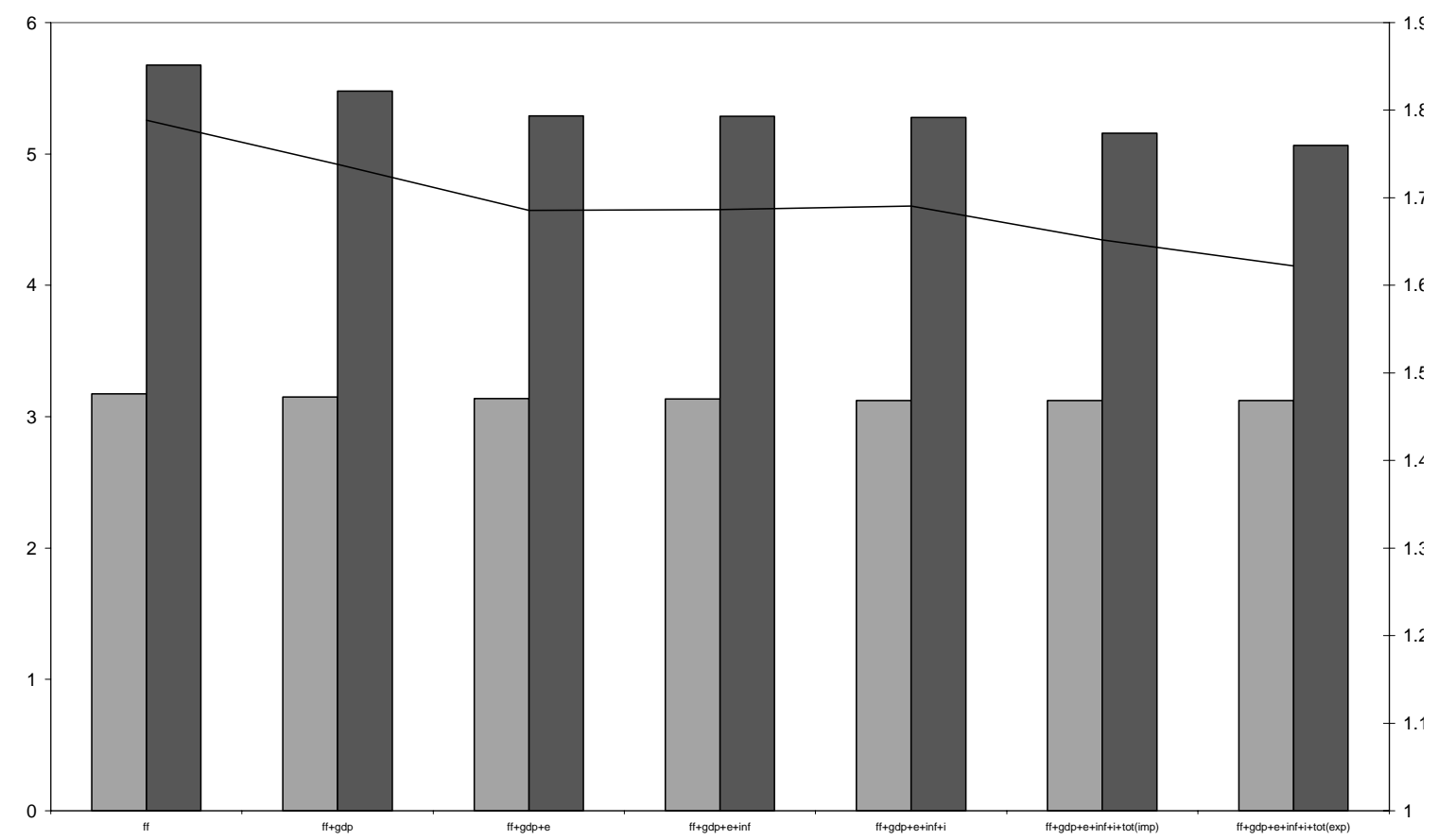

\section{B. External Factors}

Apart from domestic factors, capital flows should also depend on international factors, such as international interest rates. In this section, we control for the US real interest rate, constructed as the difference between the US short-run nominal interest rate and US inflation. ${ }^{9}$

In Table 3 the results are summarized. We run the same specifications run before, were we first introduce the real interest rate in the regression and then each of the macroeconomic variables is added one by one. In Table 3 we only present the results of the first and last of these regressions. We compare them to the benchmark and the regression with all the macroeconomic variables.

The possibility of contagion may also be considered as an external factor, but in the absence of a clear fundamental counterpart, we consider contagion in the next section on statistical properties of capital flows. However, several theories of contagion have argued that it should be reflected in international interest rates; hence, at least in this sense the introduction of the US short-term interest rate is also controlling for contagion. 
External factors have very little explanatory power; the " $\mathrm{R}$ ", is only 1 percent for emerging countries and 0.2 percent for developed economies. Comparing the third and fourth rows it can also be concluded that international interest rate movements are already included in some of the macroeconomic variables that we considered in the previous sub-section. Once we account for domestic factors, the US interest rate increases the " $\mathrm{R}^{2 \text { " }}$ by less than 0.1 percent. This suggests that some of the explanatory power of domestic variables for emerging countries actually reflected the (limited) response to international interest rates.

\begin{tabular}{|c|c|c|c|c|c|c|c|c|}
\hline & \multicolumn{3}{|c|}{ developed countries } & \multicolumn{3}{|c|}{ emerging countries } & \multicolumn{2}{|c|}{ ratios } \\
\hline & $" \mathrm{R}^{2 \%}$ & st dev & skewness & $" \mathrm{R}^{2 \%}$ & st dev & skewness & st dev & skewness \\
\hline $\mathrm{ff}$ & $0.0 \%$ & 3.175 & -0.502 & $0.0 \%$ & 5.677 & -0.760 & 1.788 & 1.516 \\
\hline ff+rius & $0.2 \%$ & 3.172 & -0.500 & $1.0 \%$ & 5.648 & -0.752 & 1.781 & 1.505 \\
\hline$f f+g d p+e+i n f+i+\operatorname{tot}(\exp )$ & $3.3 \%$ & 3.122 & -0.511 & $20.4 \%$ & 5.064 & -0.760 & 1.622 & 1.486 \\
\hline ff + rius $+g d p+e+i n f+i+\operatorname{tot}(\exp )$ & $3.3 \%$ & 3.122 & -0.512 & $20.4 \%$ & 5.064 & -0.759 & 1.622 & 1.484 \\
\hline
\end{tabular}

Including other external factors, such as output and inflation in G7 countries, or output, nominal exchange rate and inflation from the major trading partners also has (almost) no effects on the " $\mathrm{R}^{2 \text { " }}$ and the relative standard deviations. We included these variables one by one into the specification and the US interest rate was the one that performed best in terms of " $\mathrm{R}^{2}$ ".

In summary, adding external factors to the regression does not affect significantly the standard deviation of capital flows, either the levels or the ratio between emerging and developed countries. The skewness of residuals is not affected either.

\section{Non-Linearities}

A third alternative worth exploring is the possibility of non-linear responses of capital flows to shocks to fundamentals. Such a response may account for both higher volatility and skewness. To account for this possibility we introduced non-linear terms in the regression. We introduced each of the macroeconomic variables in the regressions with a quadratic term to test for convexities and with an absolute value to test for asymmetries. We performed this exercise with each of the macroeconomic 
variables in each of the specifications. Non-linearities improved very little the " $\mathrm{R}$ " " of the regressions and they never reduced the ratio of the standard deviations bellow $1.612 .^{10}$

\section{The role of fundamentals: summary}

In summary, we find that once we account for domestic and international macroeconomic variables and non-linear effects, we are able to explain very little of the volatility of capital flows to emerging markets. In particular, we explain very little of the difference in standard deviation and skewness of capital flows between emerging and developed countries. We started by stating that capital flows to emerging countries are 78.8 percent more volatile than those to developed economies, and after controlling for all these shocks this ratio is reduced to 62.2 percent. Furthermore, it is important to restate that we are probably overestimating the explanatory power of these variables since we are ignoring endogeneity and omitted variables in the specifications.

Since we cannot explain why capital flows to emerging countries are more volatile using fundamentals, in the next section we explore some statistical properties of capital flows to help determine where the answer may be.

\section{Statistical properties of volatility: crises, persistence, and contagion.}

In this section we study the residuals from a different perspective. We assume that there is a sizeable proportion of the volatility that is non-fundamental driven and study three possibilities: the role of outliers - or what we identify as crises, the role of persistence or the lags, and the role of contagion. Notice that all these effects are in addition to the crises, persistence, and contagion that are already reflected in interest rates, exchange rates, inflation, output, and terms of trade

\footnotetext{
${ }^{10}$ Given how little difference non-linearities made, we do not report the results of these regressions. Results are available from the authors.
} 


\section{A. Crises}

In the previous sections we showed that capital flows to emerging countries are both more volatile and more left skewed than capital flows to developed countries. It seems reasonable that emerging countries crises may have a role in accounting for both observations. In this section, we analyze this possibility by looking at the effect of excluding outliers from the residuals of the regressions in the previous section. In particular, we define as outlier a residual that is more than two standard deviations away from zero, where the standard deviation is calculated country by country. We look at the effect of excluding residuals on " $\mathrm{R}^{2}$ ", the standard deviation of residuals, and skewness. The variance, standard deviation, and skewness are calculated on the residuals that remain after we exclude the outliers.

The results are presented in Table 4. We report the results for two specifications: the pure fixed effects (benchmark), and the fixed effects plus the macroeconomic controls including the US real interest rate. We compare the standard deviation of the residuals of the specification with all the residuals with the one in which we exclude the outliers.

Obviously, the elimination of the outliers reduces the variances in both samples significantly. The " $\mathrm{R}$ ", are all above 45 percent. The most surprising result, however, is that the ratio of the standard deviations is almost unaffected by this procedure. The ratio of standard deviations only falls from 1.788 to 1.754 , and from 1.622 to 1.599 in the two specifications. This procedure, however, does eliminate the skewness in the data, from an average absolute value of 0.5-0.7 to roughly 0.1 or less.

Table 4: Statistics of capital flows - domestic and external macroeconomic variables excluding outliers

\begin{tabular}{|c|c|c|c|c|c|c|c|c|}
\hline & \multicolumn{3}{|c|}{ developed countries } & \multicolumn{3}{|c|}{ emerging countries } & \multicolumn{2}{|c|}{ ratios } \\
\hline & $" \mathrm{R}^{2 \%}$ & st dev & skewness & $" \mathrm{R}^{2 \prime}$ & st dev & skewness & st dev & skewness \\
\hline $\mathrm{ff}$ & $0.0 \%$ & 3.175 & -0.502 & $0.0 \%$ & 5.677 & -0.760 & 1.788 & 1.516 \\
\hline ff + rius $+g d p+e+i n f+i+\operatorname{tot}(\exp )$ & $3.3 \%$ & 3.122 & -0.512 & $20.4 \%$ & 5.064 & -0.759 & 1.622 & 1.484 \\
\hline no outliers+ff & $46.9 \%$ & 2.313 & 0.023 & $48.9 \%$ & 4.058 & -0.144 & 1.754 & N/A \\
\hline no outliers $+f f+$ rius $+g d p+e+i n f+i+t o t(\exp )$ & $48.6 \%$ & 2.276 & -0.025 & $58.9 \%$ & 3.639 & 0.007 & 1.599 & N/A \\
\hline
\end{tabular}

Although not reported, kurtosis is also reduced from between 5 and 6 to close to 3 using this procedure. Therefore, the outliers explain the non-normal behavior of the distribution of residuals. However, they do not account for the higher volatility of capital flows to emerging countries. These results are robust to all the previous specifications described so far. 


\section{B. Persistence}

In this section we study the possibility that shocks have different persistence in emerging and developed countries. Persistence is not a typical "fundamental" included in the theories of capital flows, and that is why we think of persistence as a statistical property of capital flows. We study the issue of persistence by adding lags to two specifications, fixed effects, and all macroeconomic controls excluding outliers. First, we add the lag of the capital flows alone. Second, we include the lags of the macroeconomic variables as well.

Table 5: Statistics of capital flows - domestic and external macroeconomic variables with lags

\begin{tabular}{|c|c|c|c|c|c|c|c|c|}
\hline & \multicolumn{3}{|c|}{ developed countries } & \multicolumn{3}{|c|}{ emerging countries } & \multicolumn{2}{|c|}{ ratios } \\
\hline no outliers $+f f+$ rius $+g d p+e+i n f+i+\operatorname{tot}(\exp )$ & $3.3 \%$ & 3.122 & & $20.4 \%$ & 5.064 & & 1.622 & \\
\hline lag(kf)+no outliers+ff+rius+gdp+e+inf $+i+\operatorname{tot}(\exp )$ & $65.4 \%$ & 1.867 & 0.475 & $82.3 \%$ & 2.389 & 0.607 & 1.258 & 1.278 \\
\hline full lags+no outliers+ff+rius+gdp+e+inf $+\mathrm{i}+\operatorname{tot}(\exp )$ & $65.0 \%$ & 1.877 & 0.481 & $81.6 \%$ & 2.437 & 0.578 & 1.298 & 1.201 \\
\hline
\end{tabular}

A summary of the results is presented in Table $5 .{ }^{11}$ Since the skewness was entirely accounted for by excluding outliers, we do not report this statistic anymore. Instead, we report the coefficient on the lag of the capital flows. The first row is our benchmark; the second row is our regression with all the macroeconomic variables and excluding outliers. The third row is the regression where we only control for fixed effects and the lag of capital flows. The fourth row is the specification with the lag and all the macroeconomic variables and no outliers. The last row includes the lags of all the right hand side variables as well.

Notice, first, that persistence accounts for a large fraction of capital flow volatility. The " $\mathrm{R}^{2 \text { " }}$ of just including the lag of capital flows is 41 percent for emerging countries, and 25 percent for developed countries. Once we account for macroeconomic controls and outliers, the " $R$ " " increases to 65 percent for developed countries and 82 percent for emerging countries.

11 As in the previous sections we also performed the same test for all the possible specifications and here we only report some of them. 
Interestingly, and contrary to the effect of the exclusion of outliers, accounting for persistence not only increases the "explanatory" power of our regressions but also decreases substantially the ratio of standard deviations. This is reflected in the different coefficients of lag capital flows, which is quite higher for emerging countries than for developed countries, showing that capital flows are more persistent in emerging than in developed countries. The coefficient on the lag in emerging countries is usually higher than 0.60 while it is below 0.50 for developed countries.

In addition, whereas the exclusion of outliers before had little effect on the ratio of residuals, once we account for different persistence the exclusion of outliers does have a significant effect on this ratio. The combined effect of accounting for persistence and excluding outliers is to reduce the ratio of standard deviations from 1.788 to $1.298 .^{12}$

\section{Contagion}

The last statistical property of capital flows we analyze is the co-movement of flows across countries not explained by macroeconomic variables. We denote this co-movement as contagion.

We construct a common component of capital flows for different groups of countries, and study to what extent these common components explain capital flows in each group. The groups are: Latin America, Asia, Eastern Europe, other emerging, and developed countries. We try two methodologies to construct the common component. First, we consider a true common component computed by the first principal component. The problem with this measure is that we do not have a long enough time series and, therefore, not all countries can be included to form the principal component. This is clearly an underestimate of the common factor. As a result, we use an alternative simpler methodology in which the common component is simply the average capital flows for the group in each year. For each methodology, we added the principal component to the right hand side of our regressions.

12 We do not know why the effect of excluding residuals on the ratio of standard deviations is more important once we account for persistence. One possibility is that "crises" in emerging countries follow periods of high capital inflows more so than in developed countries. As a result, accounting for persistence increases the "expected" inflow right before the crisis in emerging countries more than in developed countries, increasing the relative size of the negative innovation. 
Table 6: Statistics of capital flows - domestic and external macroeconomic variables with lags

\begin{tabular}{|c|c|c|c|c|c|c|c|c|}
\hline & \multicolumn{3}{|c|}{ developed countries } & \multicolumn{3}{|c|}{ emerging countries } & \multicolumn{2}{|c|}{ ratios } \\
\hline & "R $\mathrm{R}^{2 \%}$ & st dev & lag coef & "R ${ }^{2 "}$ & st dev & lag coef & st dev & lag coef \\
\hline ff & $0.0 \%$ & 3.175 & & $0.0 \%$ & 5.677 & & 1.788 & \\
\hline lag $(\mathrm{kf})+$ no out $+\mathrm{ff}+$ rius $+\mathrm{gdp}+\mathrm{e}+\mathrm{inf}+\mathrm{i}+\mathrm{tot}(\exp )$ & $65.0 \%$ & 1.877 & 0.481 & $81.6 \%$ & 2.437 & 0.578 & 1.298 & 1.201 \\
\hline $\mathrm{pc}+\mathrm{ff}+$ rius & $2.6 \%$ & 3.132 & & $4.1 \%$ & 5.559 & & 1.775 & \\
\hline pcave+ff+rius & $4.6 \%$ & 3.100 & & $39.0 \%$ & 4.433 & & 1.430 & \\
\hline $\mathrm{pc}+\mathrm{lag}(\mathrm{kf})+$ no out $+\mathrm{ff}+$ rius $+\mathrm{gdp}+\mathrm{e}+\mathrm{inf}+\mathrm{i}+\mathrm{tot}(\exp )$ & $65.5 \%$ & 1.864 & 0.491 & $84.5 \%$ & 2.237 & 0.586 & 1.200 & 1.194 \\
\hline pcave+lag $(k f)+$ no out+ff+rius $+g d p+e+i n f+i+\operatorname{tot}(\exp )$ & $61.8 \%$ & 1.961 & 0.509 & $83.9 \%$ & 2.277 & 0.573 & 1.161 & 1.127 \\
\hline
\end{tabular}

The results are summarized in table 6 . The third and fifth rows present the results of adding the principal component constructed with the first methodology (pc), while the fourth and sixth rows present the results of adding the principal component constructed with the second methodology (pcave). Observing the results of the third and fourth rows, it seems clear that the principal components may explain a substantial fraction of capital flows volatility, especially for emerging countries. However, this depends very much on the methodology used to construct the principal components, and it is not clear which one should be preferred..$^{13}$ Observing the results of the fifth and sixth rows, it seems that the principal components also have some explanatory power when we also consider persistence and outliers for the case of emerging countries, although not for the case of developed countries. As a result, the ratio of standard deviations is further reduced to below 1.200.

We showed that capital flows to emerging countries are more correlated than capital flows to developed countries. As a result, when we add common components to the regressions we reduce the relative volatility of capital flows to emerging countries. One shortcoming of this exercise is that we cannot determine if this result is due to contagion or to an unobserved common determinant of capital flows to emerging countries. But regardless of the explanation for the result, we can say that common external conditions must play a significant role in capital flows to emerging countries, and that these common external conditions have little to do with international interest rates.

13 If we had a longer time series we would trust more the results of the regressions in which the principal components are constructed in the traditional way; however, we do not have such data available to us. The main problem is that to to estimate principal components we need as many time observations as series are to be included. This is impossible for the Eastern European countries in which the information we have is at most 10 years long. 


\section{Summary}

Figure 3 shows the ratio of standard deviations of capital flows to emerging countries relative to developed countries for most specifications run. On the $\mathrm{x}$-axis we have all the regressions, in which we control for domestic macroeconomic variables, international interest rates, outliers, persistence, and contagion. The bars represent the standard deviation of the residuals measured in the left vertical axis, and the line shows the ratio of standard deviations measured in the right vertical axis. A measure of the explanatory power is to compare the size of the bars to the first one on the left (which corresponds to our benchmark).

As we have argued before, macroeconomic controls and international interest rates have a small effect on the volatility of residuals and almost no effect on the ratio of standard deviations. This is

despite the fact that endogeneity and omitted variables suggest that the little we explain is probably an overestimation of the actual effect of these variables. 
Figure 3: Standard deviation for each group for all specifications.

Ratio of standard deviations is measured on the right hand axis.

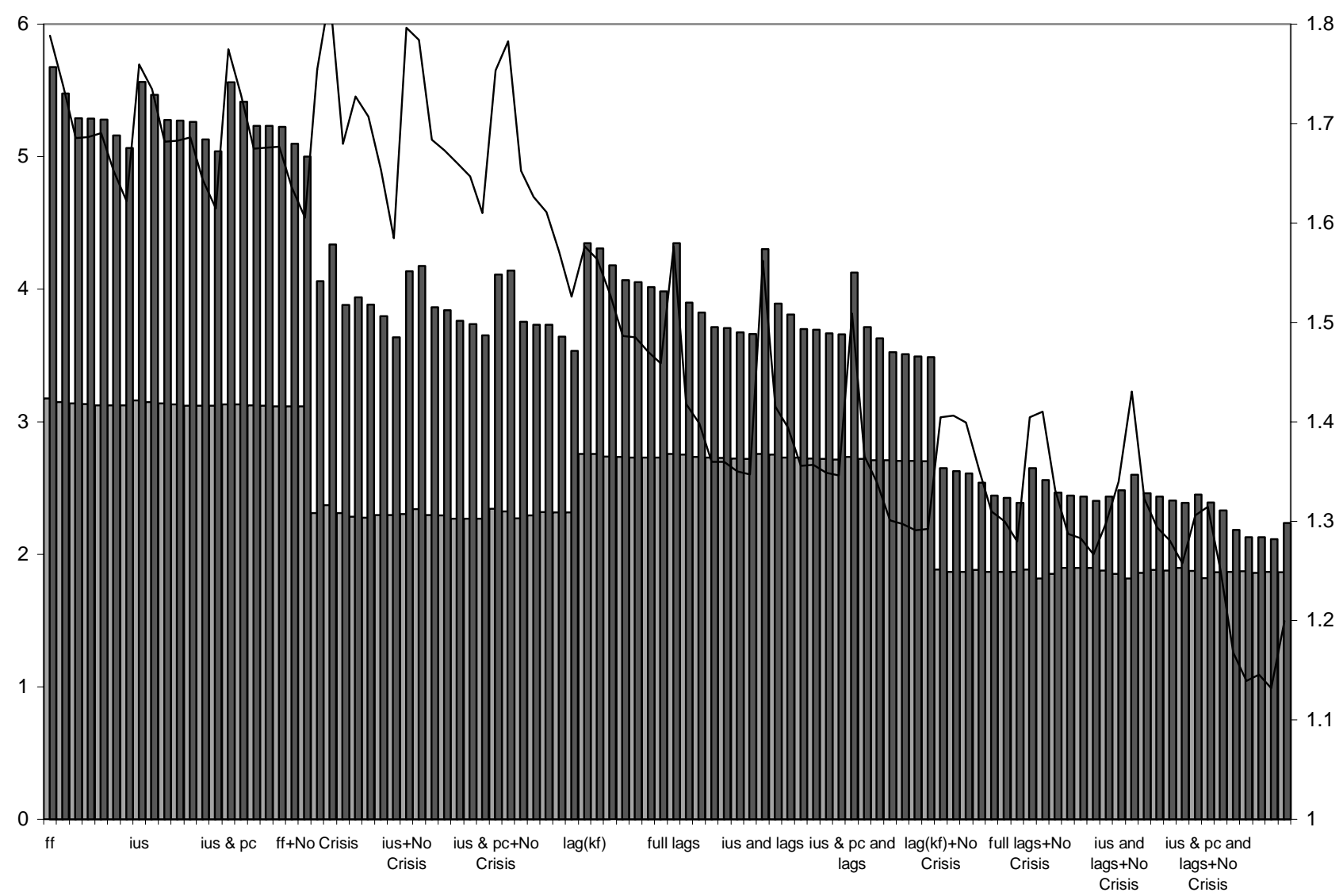

In the following specifications, we examine whether the statistic properties of capital flows can shed light on possible explanations for the volatility of capital flows to emerging countries. We find that capital flows to emerging countries have three properties, which account for almost all the excess standard deviation. Capital flows to emerging countries are more characterized by crises, are more persistent, and are more correlated with capital flows to similar countries than capital flows to developed countries. Once we control for these differences, the ratio of standard deviations of residuals drops from 1.788 to 1.161 .

The fact that crises cannot be accounted for by domestic macroeconomic variables, together with the fact that capital flows to emerging countries are quite correlated suggests the importance of external 
or "supply" factors in explaining such flows. ${ }^{14}$ Interestingly, international interest rates have very little explanatory power as well, suggesting that it is not the "representative world consumer" who supplies capital to emerging countries. In other words, the market for capital to emerging countries is probably somewhat segmented, subject to shocks unrelated to domestic macroeconomic conditions, and characterized by contagion. These conclusions might not be surprising. What we do find surprising is how much of the excess volatility of capital flows to emerging countries these characteristics can account for, especially when compared to the negligible effect of domestic macroeconomic variables and world interest rates.

In addition to crises and common components, we find that capital flows to emerging countries are substantially more persistent than those to developed countries. In Figure 4, we present the auto regressive coefficient of capital flows for different specifications. The coefficient is quite stable across specifications, being around 0.60 for emerging countries and 0.49 for developed countries. These coefficients imply a half-life of capital flow shocks of 16.3 months for emerging countries and 11.7 months for developed countries. The difference in the persistence of shocks explains a large part of the ratio of standard deviations between emerging and developed countries. As far as we know, we do not have theories explaining this different degree of persistence.

Broner, Lorenzoni, and Schmukler (2004) present evidence on emerging countries sovereign debt that suggests the importance of these supply factors. See this paper and Caballero and Krishnamurthy (2003) for models in which supply side considerations play a major role in the access of emerging economies to international capital markets. 
Figure 4: Auto regressive coefficient.

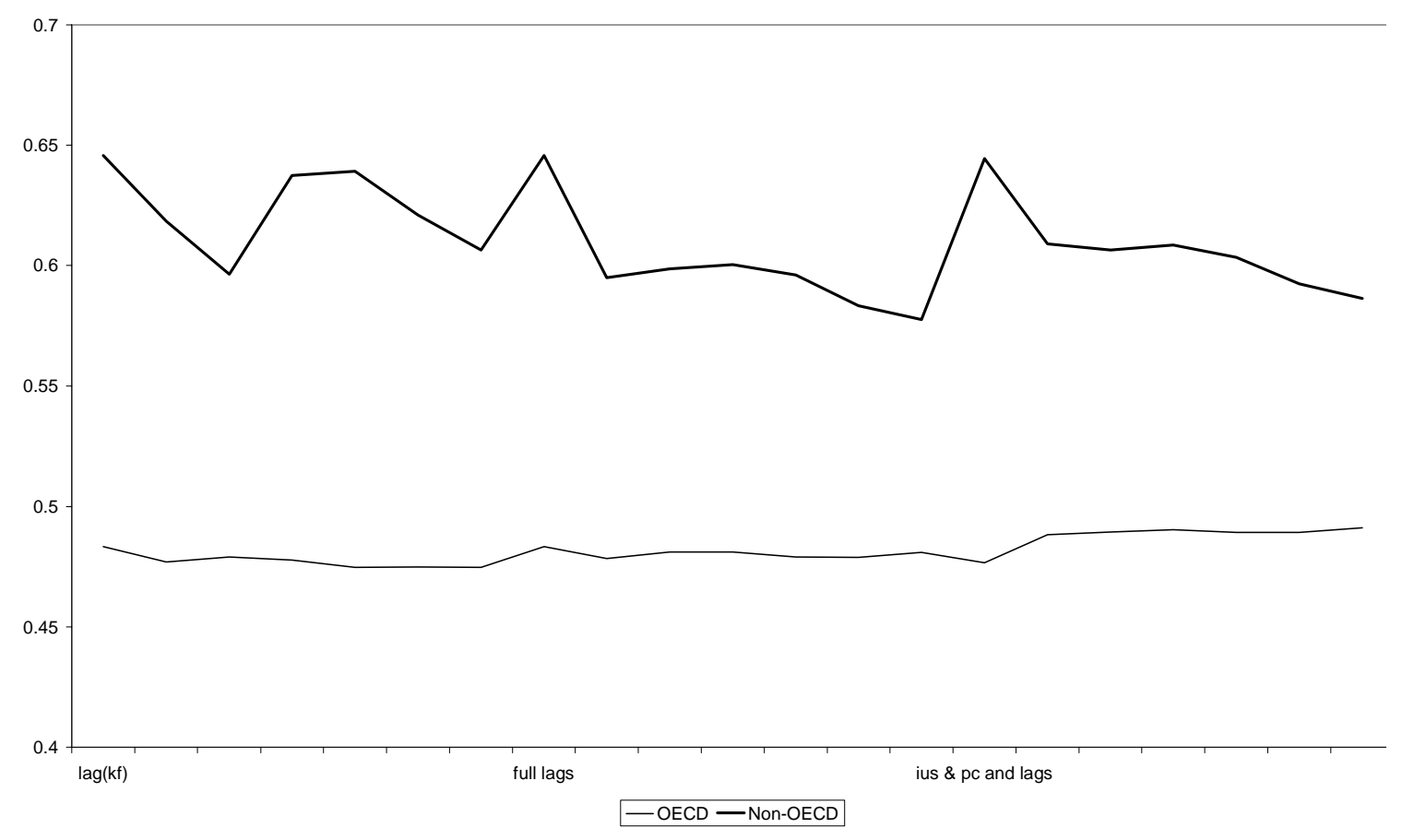

\section{Volatility and country characteristics}

In the previous sections we showed that capital flows to emerging countries are much more volatile than capital flows to developed countries. We also showed that macroeconomic controls had little explanatory power to explain this phenomenon, which was characterized by a set of statistical properties not obviously related to any fundamentals. In this section we take a step back and analyze whether fundamentals may explain, if not the time series behavior of capital flows, at least its unconditional standard deviation. From our previous results it seems that the level of economic development should be a good predictor for this volatility, but it is not clear which aspect of economic development is most relevant. In this section we consider three variables which are correlated with economic development but which reflect different economic characteristics of countries: income per capita, financial development, and quality of institutions.

For income per capita we used the average of real income per capita from Penn World Tables for the period 1985-1989. For financial development we use the ratio of private domestic credit to GDP, 
and the ratio of liquid liabilities to GDP in 1989 (source: Loayza, Fajnzylber and Calderón 2004). For quality of institutions we use the first principal component of indicators on prevalence of law and order, quality of bureaucracy, absence of corruption, and accountability of public officials in 1989 (source: International Country Risk Guide). We regress capital flow volatility during the period 19902003 on these country characteristics. The reason why we study capital flow volatility starting in 1990 is that we want to minimize the problem of reverse causality, namely, that country characteristics in 1989 be the result of past capital flow volatility.

Table 7 shows the main results. We find that higher per capita GDP, a higher level of financial development, and a higher level of institutional quality are all associated with less volatile capital flows. The results for financial development are especially interesting. While a high level of private credit is associated with less capital flow volatility, the result is weaker for the level of liquid liabilities. The reason is probably that while the two measures reflect both financial development and, to some degree, financial vulnerability (e.g. leverage), the level of liquid liabilities probably reflects financial vulnerability to a larger extent than the level of private credit. This interpretation is reinforced by the result of the regression in which both measures are included (regression 4). In this case the coefficient on private credit increases in size while the coefficient on liquid liabilities becomes positive. Given the small number of observations and the high correlation between the explanatory variables, none of them is significant when included simultaneously. If one is willing to associate p-value with explanatory power, it seems that financial development is the variable that retains the most explanatory power, followed by institutional quality, and then by per capita GDP.

Table 7: Volatility regressions

\begin{tabular}{|c|c|c|c|c|c|c|}
\hline cap flow volatility $1990-2003$ & (1) & (2) & (3) & (4) & (5) & (6) \\
\hline per capita GDP & $\begin{array}{r}-\mathbf{0 . 1 1} * * \\
(0.05) \\
\end{array}$ & & & & & $\begin{array}{r}-0.04 \\
(0.14) \\
\end{array}$ \\
\hline fin devel: priv cred & & $\begin{array}{r}-\mathbf{- 0 . 0 1 4} * \\
(0.008) \\
\end{array}$ & & $\begin{array}{r}-0.019 \\
(0.013) \\
\end{array}$ & & $\begin{array}{r}-0.008 \\
(0.016) \\
\end{array}$ \\
\hline fin devel: liq liab & & & $\begin{array}{c}-0.011 \\
(0.011)\end{array}$ & $\begin{array}{r}0.009 \\
(0.018) \\
\end{array}$ & & $\begin{array}{r}0.007 \\
(0.018) \\
\end{array}$ \\
\hline institutional quality & & & & & $\begin{array}{r}-\mathbf{0 . 4 3} * * \\
(0.20) \\
\end{array}$ & $\begin{array}{r}-0.21 \\
(0.54) \\
\end{array}$ \\
\hline $\mathrm{R}^{2}$ & $10.8 \%$ & $6.9 \%$ & $2.6 \%$ & $7.5 \%$ & $10.4 \%$ & $11.3 \%$ \\
\hline obs & 53 & 43 & 43 & 43 & 43 & 43 \\
\hline \multicolumn{7}{|c|}{$\begin{array}{l}\text { Notes: The dependent variable is the standard deviation of capital flows between } 1990 \text { and } 2003 \text {. The independent } \\
\text { variables are as of } 1989 \text {, except per capita GDP that is the average over the period 1985-1989. Bold numbers denote } \\
\text { significance at least at } 10 \% \text { level. *, **, and } * * * \text { denote } 10 \%, 5 \% \text {, and } 1 \% \text { significance, respectively. Standard errors in } \\
\text { parenthesis. Units are: capital flows (for standard deviation) as percentage of GDP, per capita GDP in thousands of } \\
\text { dollars, financial development as percentage of GDP (both private credit and liquid liabilities), institutional quality is an } \\
\text { index (in } 1990 \text { it ranges from }-3.26 \text { for Zaire (not in our sample) or }-2.06 \text { for Nigeria (in our sample) to } 3.47 \text { for Canada }\end{array}$} \\
\hline
\end{tabular}


We also tried controlling for the volatility of the explanatory variables to make sure they do not affect the volatility of capital flows through their effects on the main equations. The results are in table 8. In principle we would have wanted to control for the volatility of the control variables during the 80's, since it is possible that volatility of both controls and capital flows during the 90's be affected by unobserved variables. However, we only have data of volatility during the 80's for per capita GDP, so for the other controls we could only use volatility during the 90's. We find that controlling for the volatility of the control variables does not qualitatively affect the results of Table 7 , in the sense that the estimated coefficients are not statistically different, except perhaps in the case of quality of institutions for which the magnitude of the coefficient seems to increase. Again, when including all four controls simultaneously they all become insignificant. And if one is willing to associate p-value with explanatory power, both financial development and institutional quality have a bit more explanatory power than by per capita GDP. ${ }^{15}$

Table 8: Volatility regressions controlling for volatility in explanatory variables

\begin{tabular}{|c|c|c|c|c|c|c|c|c|c|c|}
\hline $\begin{array}{l}\text { cap flow vol } \\
1990-2003\end{array}$ & (1) & (2) & (3) & (4) & (5) & (6) & (7) & (8) & (9) & (10) \\
\hline $\begin{array}{l}\text { per capita } \\
\text { GDP }\end{array}$ & $\begin{array}{r}-\mathbf{- 0 . 1 8} * * * * \\
(0.05)\end{array}$ & & & & $\begin{array}{r}-0.01 \\
(0.15)\end{array}$ & $\begin{array}{l}\mathbf{- 0 . 1 7 *} \\
(0.09)\end{array}$ & & & & $\begin{array}{l}-0.22 \\
(0.18) \\
\end{array}$ \\
\hline $\begin{array}{l}\text { fin dev: } \\
\text { priv cred }\end{array}$ & & $\begin{array}{r}\mathbf{- 0 . 0 1 8} * * * \\
(0.008) \\
\end{array}$ & & & $\begin{array}{r}-0.011 \\
(0.017) \\
\end{array}$ & & $\begin{array}{r}-0.014 \\
(0.011)\end{array}$ & & & $\begin{array}{r}-0.011 \\
(0.016)\end{array}$ \\
\hline $\begin{array}{l}\text { fin dev: } \\
\text { liq liab }\end{array}$ & & & $\begin{array}{r}-0.016 \\
(0.011)\end{array}$ & & $\begin{array}{r}0.013 \\
(0.019)\end{array}$ & & & $\begin{array}{l}-0.007 \\
(0.012)\end{array}$ & & $\begin{array}{r}0.006 \\
(0.018)\end{array}$ \\
\hline inst. quality & & & & $\begin{array}{r}-\mathbf{0 . 8 3} * * * \\
(0.28) \\
\end{array}$ & $\begin{array}{r}-0.92 \\
(0.59) \\
\end{array}$ & & & & $\begin{array}{c}-\mathbf{- 0 . 5 8 *} \\
(0.30)\end{array}$ & $\begin{array}{r}0.04 \\
(0.56) \\
\end{array}$ \\
\hline $\begin{array}{l}\text { st dev } \\
\text { GDP 90s }\end{array}$ & $\begin{array}{r}\mathbf{1 . 0 2}^{* * *} \\
(0.47)\end{array}$ & & & & $\begin{array}{r}0.71 \\
(0.63)\end{array}$ & & & & & \\
\hline $\begin{array}{l}\text { st dev } \\
\text { priv cred }\end{array}$ & & $\begin{array}{c}\mathbf{0 . 0 7 9}^{*} \\
(0.045)\end{array}$ & & & $\begin{array}{r}0.063 \\
(0.048)\end{array}$ & & & & & \\
\hline $\begin{array}{l}\text { st dev } \\
\text { liq liab }\end{array}$ & & & $\begin{array}{r}0.081 \\
(0.050)\end{array}$ & & $\begin{array}{r}0.029 \\
(0.063)\end{array}$ & & & & & \\
\hline $\begin{array}{l}\text { st dev } \\
\text { ins qual }\end{array}$ & & & & $\begin{array}{l}\mathbf{- 3 . 2 9 *} \\
(1.72)\end{array}$ & $\begin{array}{r}-3.23 \\
(1.88)\end{array}$ & & & & & \\
\hline $\begin{array}{l}\text { st dev } \\
\text { GDP } 80 \text { s }\end{array}$ & & & & & & $\begin{array}{r}1.00 \\
(1.13) \\
\end{array}$ & $\begin{array}{r}0.01 \\
(0.87) \\
\end{array}$ & $\begin{array}{r}-0.52 \\
(0.76) \\
\end{array}$ & $\begin{array}{r}0.66 \\
(0.96) \\
\end{array}$ & $\begin{array}{r}1.99 \\
(1.38) \\
\end{array}$ \\
\hline $\mathrm{R}^{2}$ & $18.4 \%$ & $13.6 \%$ & $8.6 \%$ & $18.0 \%$ & $30.9 \%$ & $12.1 \%$ & $6.9 \%$ & $3.8 \%$ & $11.5 \%$ & $16.0 \%$ \\
\hline obs & 53 & 43 & 43 & 43 & 43 & 46 & 43 & 43 & 43 & 43 \\
\hline
\end{tabular}

Notes: The dependent variable is the standard deviation of capital flows between 1990 and 2003. The independent variables are as of 1989, except per capita GDP that is the average over the period 1985-1989. Bold numbers denote significance at least at 10\% level. *, **, and *** denote 10\%, $5 \%$, and $1 \%$ significance, respectively. Standard errors in parenthesis. Units are: capital flows (for standard deviation) as percentage of GDP, per capita GDP in thousands of dollars, financial development as percentage of GDP (both private credit and liquid liabilities), institutional quality is an index (in 1990 it ranges from -3.26 for Zaire (not in our sample) or -2.06 for Nigeria (in our sample) to 3.47 for Canada). 


\section{Final Remarks}

In this paper we provide a number of stylized facts about capital flows to emerging and developed countries: (i) Capital flows to emerging countries are much more volatile than capital flows to developed countries. (ii) Fundamentals, in the form of domestic and foreign macroeconomic variables, explain very little of the dynamics of capital flows. (iii) Fundamentals, in the form of country characteristics, explain a substantial amount of the unconditional volatility of capital flows across countries: financial development, good institutions, and high income per capita are all associated with lower volatility. (iv) Although we cannot explain the dynamics of capital flows, the high volatility of capital flows to emerging countries reflects three statistical properties of capital flows: flows to emerging countries have fatter left tales, i.e. emerging countries are more subject to "crises"; shocks to capital flows are more persistent in emerging countries; and capital flows to emerging countries are more correlated across countries.

Although our evidence is more suggestive than conclusive, overall, it points to the importance of supply side factors in explaining capital flows to emerging countries. The fact that domestic macroeconomic variables have little explanatory power indicates that demand factors cannot account for much of the dynamics of capital flows to emerging countries. The importance of a common component of capital flows also suggests that external factors play an important role in explaining capital flows to emerging countries. Furthermore, the fact that crises are more important in emerging countries suggests that these external factors are subject to sudden changes. These observations are consistent with a world in which emerging countries are not fully integrated into global capital markets, but rather participate in a somewhat segmented market subject to sudden shifts in the supply of capital. However, it would be wrong to conclude that emerging countries cannot do anything to avoid being subject to very volatile capital flows. Even though fundamentals explain little of the dynamics of capital flows, they do account for a substantial fraction of the unconditional volatility of flows. Our evidence suggests that emerging countries can reduce the volatility of capital flows by improving their financial markets and institutions. 


\section{References}

Broner, F., G. Lorenzoni, and S. Schmukler, (2004), "Why do emerging economies borrow short term?" mimeo.

Caballero, R., and A. Krishnamurthy, (2003), "Excessive Dollar Debt: Financial Development and Underinsurance," Journal of Finance, 58:2, 867-893.

Loayza, N., P. Fajnzylber, and C. Caldern. (2004) Forthcoming. Economic Growth in Latin America and the Caribbean: Stylized Facts, Explanations, and Forecasts. Washington, D.C: The World Bank.

Ricardo Hausmann, Ugo Panizza, Roberto Rigobon (2004) “The Long-Run Volatility Puzzle of the Real Exchange Rate” NBER 10751. 